\title{
Study on Small Component Thermal Ignition Compliance meeting IEC Standard
}

\author{
Qin Xue \\ Xi'an Research Institute of China Coal Technology Engineering Group Corp, Xi'an, China
}

\begin{abstract}
With the supplement and revision of IEC standard, the thermal ignition test of small components has been stipulated. Small component ignition test apparatus is testing equipment of intrinsically safe electrical products about thermal ignition. Its research and application is an important link of energy storage components for energy control and temperature control. This paper starts from the analysis of restraining measures of capacitor and inductance energy storage, its system composition, main technical requirements and working principle of small component ignition test apparatus are systematically introduced. Then, the influence of the surface area of heat source in the calibration circuit on the minimum ignition temperature of the mixture of methane and air is demonstrated. From the running situation and the experimental data, the apparatus has the ability to carry out various small components ignition inspection.
\end{abstract}

\section{General Instructions}

With continuous improvement of the level of industrial automation, explosive areas of intrinsic safety electrical equipment is widely used in coal and petroleum chemical industry. The method of intrinsically safe equipment design and inspection is to limit the electric spark and heat energy of the two light source. In order to evaluate intrinsically safe performance of the electrical circuit, the intrinsically safe equipment must be carried out ignited evaluation and test validation in an inspection institution with relevant qualifications. After passing the inspection, it can be used in a potentially explosive environment ${ }^{[1]}$. So far the evaluation method and apparatus of spark ignition have become mature, however, there is little mention of the thermal effect ignition evaluation methods and test apparatuss.

In recent years, with the supplement and revision of IEC standard, the ignition test of small components has been stipulated ${ }^{[2]}$. The thermal effect is controlled by surface temperature of the component, it can exceed the standard surface temperature for small components. But it is necessary to test the resistance, potentiometer and other components of the electrical equipment in the explosive gas environment to ignite the flammable gas mixture by the small component ignition test apparatus. Due to the specific description of IEC standard only provides the technical requirements without testing apparatus, the development of small component ignition test apparatus can fill detecting ability of detection institutions.

\section{Thermal effect control of small component}

The design of equipment protection by intrinsic safety $" i$ " must start from the limit of energy, through reliably limit voltage and current in circuit within the permissible range. In order to ensure that the equipment in normal operation or the damage of small components and other circumstances, the thermal effect cannot cause the dangerous gas explosion around it. Therefore, in order to control the maximum surface temperature, the following measures can be adopted to reduce the thermal effect of small components and wires, so as to ensure that the explosive gas can avoid explosion caused by the exposure to the thermal surface higher than its natural temperature.

Selection of small components. In the design of intrinsically safe circuit, maximum power of components must be calculated in the most unfavourable working conditions or fault condition. At the same time, the value is not greater than the $2 / 3$ of the selected component rating ${ }^{3]}$. The surface temperature of the component should be measured to determine whether allowable temperature requirement is met.

Encapsulation of small components. If some small components temperature is too high to meet the

\footnotetext{
Corresponding author: xueqin@cctegxian.com
} 
temperature requirement of their group, the heat dissipation measures can be used to meet the temperature requirements. For example, the method of enlarging the encapsulation area and metal heat sink can be adopted. The volume and thickness of sealant shall reduce the maximum surface temperature of sealed component to the prescribed temperature. At the same time, the rated continuous operating temperature of sealant shall not be less than maximum temperature of sealed component.

\section{Thermal ignition assessment of small component}

Methods of circuit analysis and theoretical calculation are usually used in thermal ignition assessment. According to IEC 60079-0 standard requirements, the calculation method of thermal resistance constant and linear interpolation method are presented in this paper. It determines temperature group and power dissipation of components by means of total surface area greater than $20 \mathrm{~mm}^{2}$. Otherwise, the applicable assessment method can be judged according to whether thermal ignition is limited by encapsulation.

\subsection{Thermal resistance constant method}

According to definition of thermal resistance constant, hindrance ability of heat conduction is proportional to the length of conduction path, and inversely proportional to the thermal conductivity of material. Therefore, it is possible to derive the formula for calculating component surface temperature under the fault condition by using the thermal resistance constant.

The surface temperature $(T)$ is equal to product of component dissipation power under normal operation and prescribed fault condition $(P)$ and thermal resistance constant $(R)$, additionally the maximum environmental temperature $\left(T_{\mathrm{a}}\right)$ of the whole machine is added ${ }^{[5]}$.

Some small components are selected to organize test according to the derived formula, The experimental conditions is controlled (ambient temperature is $24^{\circ} \mathrm{C}$ ). By using thermal resistance constant, maximum surface temperature of small component in fault condition is obtained, as shown in Table 1.

Table 1. Thermal resistance constant method record table.

\begin{tabular}{|c|c|c|c|}
\hline $\begin{array}{c}\text { Component } \\
\text { Name }\end{array}$ & $\begin{array}{c}\text { Test power } \\
/ \mathrm{W}\end{array}$ & $\begin{array}{c}\text { Thermal resistance } \\
\text { constant } \\
/{ }^{\circ} \mathrm{CW}^{-1}\end{array}$ & $\begin{array}{c}\text { surface } \\
\text { temperature } \\
/{ }^{\circ} \mathrm{C}\end{array}$ \\
\hline Resistance & 0.3513 & 39.98 & 54.1 \\
\hline $\begin{array}{c}\text { Light-emitting } \\
\text { diode }\end{array}$ & 0.2119 & 89.24 & 58.9 \\
\hline diode & 0.2148 & 56.13 & 52.1 \\
\hline $\begin{array}{c}\text { Field-effect } \\
\text { transistor }\end{array}$ & 0.3711 & 16.62 & 46.2 \\
\hline
\end{tabular}

\subsection{Linear interpolation method}

The resistance constant method is not applicable to judge surface temperature of embedded small component. In design process, it considering the number of electronic components including wire wound resistor, the surface temperature rise and power dissipation can be equivalent to a linear relationship ${ }^{[6]}$, so you can find a way to take value without knowing thermal resistance constant, only judging component temperature rise by experiment.

Suppose that Test power $\mathrm{P}_{1}$ and $\mathrm{P}_{2}$ are component power in two working states, and component surface temperature can be measured by thermocouple, $\mathrm{T}_{1}$ and $\mathrm{T}_{2}$ are component surface temperature corresponding to above power.

The linear interpolation method can be used to obtain component surface temperature under fault condition, and encapsulation compound surface temperature can also be obtained directly by this method. The maximum surface temperature of small component is obtained by linear interpolation method in fault condition, as shown in Table 2.

Table 2. linear interpolation method record table.

\begin{tabular}{|c|c|c|c|c|c|}
\hline $\begin{array}{c}\text { Component } \\
\text { Name }\end{array}$ & $\begin{array}{c}\text { Test power } \\
\left(\mathrm{P}_{1}\right) \\
/ \mathrm{W}\end{array}$ & $\begin{array}{c}\text { Test power } \\
\left(\mathrm{P}_{2}\right) \\
/ \mathrm{W}\end{array}$ & $\begin{array}{c}\text { Temperature } \\
\left(\mathrm{T}_{1}\right) \\
/{ }^{\circ} \mathrm{C}\end{array}$ & $\begin{array}{c}\text { Temperature } \\
\left(\mathrm{T}_{2}\right)\end{array}$ & $\begin{array}{c}\text { surface } \\
\text { emperature } \\
/{ }^{\circ} \mathrm{C}\end{array}$ \\
\hline Resistance & 0.1248 & 0.1006 & 29 & 26 & 54.5 \\
\hline $\begin{array}{c}\text { Field-effect } \\
\text { transistor }\end{array}$ & 0.3711 & 0.2504 & 29 & 26 & 45.8 \\
\hline diode & 0.1515 & 0.0939 & 32 & 30 & 52.1 \\
\hline $\begin{array}{c}\text { Three } \\
\text { terminal } \\
\text { regulator }\end{array}$ & 0.5012 & 0.3502 & 35 & 29 & 48.1 \\
\hline
\end{tabular}

From the data of Table 1 and table 2, it can be seen that obtaining the surface temperatures values by two methods are in agreement. Therefore, it can determine surface temperature of small components in the fault condition by using thermal resistance constant calculation method and linear interpolation test method.

\section{Thermal ignition test apparatus}

For intrinsically safe equipment, the inspection process is authenticated by first evaluation and then validated. Small component is evaluated by thermal ignition, and when the surface temperature exceeds the corresponding temperature group, the small component ignition test apparatus is required to be tested and verified, as long as no ignition is considered.

\subsection{Apparatus components}

Thermal ignition test apparatus of small component is mainly composed of four parts, including ignition test flume is placed in constant temperature test chamber, gas mixing system with gas distribution facilities and display panel, control circuit unit and calibration system unit with operation and display monitoring, as shown in figure 1 . 


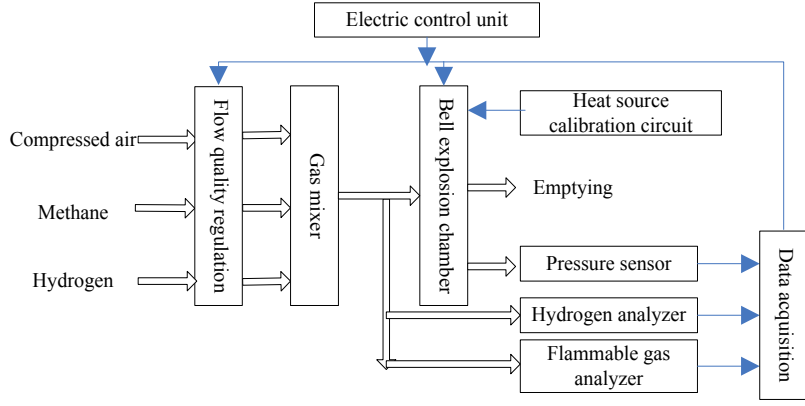

Fig. 1. Structure diagram of thermal ignition test apparatus.

Explosion chamber. It having a volume of at least 250 $\mathrm{cm}^{3}$, it can withstand blast pressure of $1.5 \mathrm{MPa}$. For group I apparatus, the test gas should be a mixture of methane and air with a methane concentration of $6.2 \%$ $6.8 \%$. There are 1 pairs of small element ignition test electrodes, 1 pairs of heating calibration electrodes and the electrode calibration temperature of 1 pairs of thermal resistance sensing electrodes in the chamber. The 3 pairs of electrodes are passed through the outer terminals of explosion-proof connectors to their respective circuits. In the test, the test component is connected to the small component ignition test electrode in the test chamber.

Gas mixing system with gas distribution apparatus and display panel. A gas distribution unit is unit gas test filter pressure after entering synchronous voltage stabilizing system, we need to control various gas flow by adjusting flow regulating valve, mix gas through flow control into mixing chamber and achieve desired concentration of mixed gas configuration ${ }^{[4]}$.

Control circuit with operation and display monitoring. The control part is provided by the microcomputer to assemble circuit into traditional computer, and interface circuit establishes the interaction between control unit and electromagnetic valve, switching relay, photoelectric sensor and calibration circuit of heat source. The concentration detection of mixed gas is carried out at the outlet of gas mixture of apparatus, and the gas analyser is connected to the reserved gas pipeline to test whether the concentration ratio meets the test requirements.

Heat source calibration system. The apparatus uses Ni$\mathrm{Cr}$ alloy resistance as heating element to produce high temperature in the self-correcting circuit. After the temperature reaches a certain value, the gas is ignited. Before and after of each series test, sensitivity of test apparatus are to check is qualified under the specified conditions in calibration circuit.

\subsection{Working principle of apparatus}

The basic working principle of apparatus is to vacuum and re-inject explosive gas mixture, then the energized test of test component. Components should be installed in electrical equipment according to the specified conditions in the test and take effective measures to ensure temperature of test mixture and flow of mixture around the components.

When the test component does not ignite or detonate in the specified test time, the calibration timing test is immediately transferred to the calibration component. It is proved that the test of small components is qualified after ignition or detonation occurs within the prescribed calibration time. Otherwise it is proved to be unqualified. When the test failed, PLC immediately control the corresponding relay to cut off two electrodes in the test circuit and open exhaust valve, and timely cleaning test chamber, clearly and completely display test conditions and test results on the display. The specific block diagram of the small component ignition test apparatus is shown in figure 2.

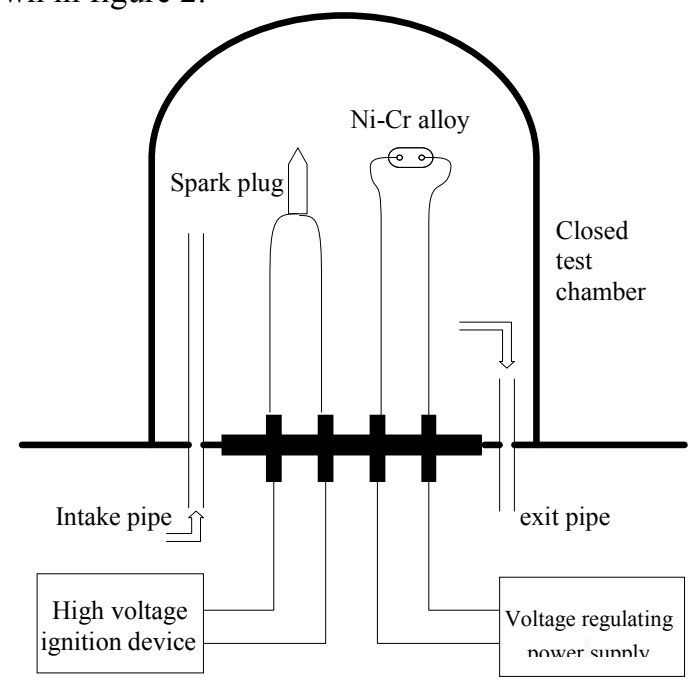

Fig. 2. Small component ignition test apparatus.

\subsection{Test verification}

The IEC standard stipulates that test should be carried out on small components when the surface temperature reaches the maximum value under the specified fault condition in special explosion-proof type. Safety margin should be obtained by improving the test environment temperature. Group I apparatus work in coal mine under the environment temperature of -20 to $+40^{\circ} \mathrm{C}$, the safety margin is $25^{\circ} \mathrm{C}$. According to requirements, the highest surface temperature should be 150 degrees, and the small components will be placed in the thermostat in the explosion container during testing, so that the small components work at the highest temperature.

The sensitivity of the apparatus is the main judgment basis for the test verification. The sensitivity of the heat source calibration circuit is related to heating-up time of $\mathrm{Ni}-\mathrm{Cr}$ alloy and ignition delay. Taking into account the criticality of ignition temperature and combustion, the self-calibration time is five minutes. The thermocouple end is placed in the small component test environment, and the other end is connected to the temperature recorder. The explosive mixture was ignited, and the sensitivity of the device was qualified. The verification record of the heat source calibration circuit is shown in table 
Table 3. Small components test verification record.

\begin{tabular}{|c|c|c|c|}
\hline Component & $\begin{array}{c}\text { Gas mixture } \\
/ \%\end{array}$ & $\begin{array}{c}\text { Ignition delay } \\
/ \mathrm{s}\end{array}$ & $\begin{array}{c}\text { Ignition } \\
\text { temperature } \\
/{ }^{\circ} \mathrm{C}\end{array}$ \\
\hline Resistance & $6.3 \%$ & 32 & 690 \\
\hline diode & $6.7 \%$ & 31 & 691 \\
\hline $\begin{array}{c}\text { Field-effect } \\
\text { transistor }\end{array}$ & $6.5 \%$ & 28 & 697 \\
\hline
\end{tabular}

\section{Conclusion}

Through thermal effect control and evaluation method to determine small component temperature group, when the temperature group is not suitable to determine its safety, the small group ignition test apparatus is used for the test verification. In order to determine test results accurately, it uses the naked eye and thermocouple to determine the method together. Through a large number of small components testing, it shows that the apparatus meets the requirements of the stipulated inspection items by IEC standard. The main technical indicators have achieved satisfactory test results.

\section{References}

1. Gang Zhang, Jianping $\mathrm{Xu}$, Shuling Fu, et al.

GB 3836.4-2010 explosive gas environment. Beijing: China Standard Press. 2011.

2. International Electrotechnical Commission.

IEC60079-0 Explosive atmospheres-Part 0:

Equipment - General requirements [M].

International Standard, Edition 6.0. (2011)

3. International Electrotechnical Commission.

IEC60079-11 Explosive atmospheres-Part11.

Equipment protection by intrinsic safety " $i "$ [M].

International Standard, Edition 6.0. (2011)

4. Chaolong Yu, Qing Liu. Development on Tri-gas dis-tribution device for intrinsically safe apparatus. Electric Explosion Protection (3): 40-43(2008)

5. $\mathrm{Yu}$ Zheng, Zhengyong Zhang. Application of constant temperature detection method in detection of mixed gas $[\mathrm{J}]$. Industrial automation (7) : 57-61 (2010)

6. Xiaonian Zhang. Analysis of the relationship between surface temperature rise and power of wirewound resistors $[\mathrm{J}]$. China electronic business (3) : 70-72.2012 